patients and their family are: reduced dietary intake, conflict over food, lack of information, lack of understanding and knowledge, and perceived neglect from Healthcare Professionals (HCPs). Therefore, there is a need from the patient and family for psychosocial and educational support from the HCP. However, this review demonstrated that the HCP also requires educational support around cachexia to be able to provide support. A theme was identified, that if a conversation began around cachexia that this would then lead onto more difficult conversations relating to death and dying, and the HCP did not feel capable of this. In summary, those HCP who routinely work within specialist palliative care appear to be more able to provide this support, whereas, for others in disciplines related to palliative care there appears to be a need for development.

\section{P-120 DEVELOPING EXCELLENT END OF LIFE DEMENTIA CARE}

Caroline Mundy. St Peter's Hospice, Bristol, UK

10.1136/bmispcare-2019-HUKNC.143

Background There is a variation both in access to high quality end of life care for people with dementia (Department of Health, 2015) and how proactive hospices are in meeting their needs (Care Quality Commission, 2016). Partnership working with dementia experts is best practice (NICE, 2018; Department of Health, 2009; National Council for Palliative Care, 2009). We identified gaps in training and wrote a twoyear strategy outlining how we would improve our dementia care and support.

Aim To enable staff to provide excellent individualised end of life care and support to patients with dementia, and their families. To promote equity of access to all hospice services for people with dementia.

Methods Formed internal dementia working group. Scoped, reviewed observations tools that aid assessment of pain and distress in people with dementia. Researched and wrote three e-learning packages for employed staff. Designed and delivered end of life dementia care study day/workshop for health/social care staff (external and internal). Initiated regular Dementia Friends sessions for staff and volunteers. Developed partnerships with dementia teams at local acute hospitals. Established strong links with local CCG commissioned community dementia service and dementia action alliance.

Results thus far Two observation tools implemented within hospice. Over 80 attendees at study day/workshop, well evaluated. Over 100 attendees of dementia friends' sessions including our hospice shop managers. A memory box now in use on the inpatient unit. Evaluation of staff knowledge and confidence planned. Delivered end of life care training to community dementia service and advised on their end of life care pathway which now incorporates the hospice $24 \mathrm{hr}$ advice line and referral process. Invitation from local hospital to deliver an End of Life Dementia Care session at their annual dementia champions study day, over 50 staff in attendance. Partnership meeting planned for acute trust dementia leads, community dementia service team manager and hospice dementia lead.

Conclusions Impact of e-learning planned, however excellent verbal feedback from staff, stating feeling more enabled. Staff report benefit of observation tools in improving assessment.

\section{P-121 RAISING AWARENESS OF PALLIATIVE CARE NEEDS OF PATIENTS WITH HEART FAILURE: AN EDUCATIONAL APPROACH}

Alison Pilsworth. LOROS Hospice, Leicester, UK

\subsection{6/bmjspcare-2019-HUKNC.144}

Funded under the St James's Place Charitable Foundation grant programme, managed by Hospice UK.

Problem identified People with heart failure, have a high burden of unmet palliative care needs. It was identified that education, support and development for team members may help (Hospice UK, 2017).

Aim To examine outcomes of a three-hour interactive heart failure workshop on perceived self-reflection of a combination of mixed health care professionals.

Methods At the start and end of the workshop the participants were asked to reflect on their understanding of heart failure, and the causes of heart failure and symptoms of heart failure. Participants were asked to identify their own personal learning objectives, these were gathered by the facilitator at the beginning and revisited at the end of the workshop.

17 workshops - 110 participants completed the questionnaire.

Results The workshops increased attendees' self-assessed understanding of heart failure and its cause and symptoms with average scores improving from 2.6 to 4.6 on a 5 point Likert scale. Before the workshop only $6 \%$ of people strongly agreed that they felt competent to care for a patient with advanced heart failure. This increased to 54\% after the workshop. $97 \%$ of participants said that their personal learning needs were met.

Discussion Following the course all participants were asked to reflect on their practice and how the course may change their care. The pathology of heart failure and how this related to symptoms was identified: 'Being able to link the mechanics of the heart for what I deal with on the ward each day.'

Participants also identified having discussions earlier and advance care planning could help also being aware of patient's prognosis.

In order to establish if application of knowledge is to be put in to practice, further research is being undertaken to explore the impact the training has had on the ability of the participants to care for patients with heart failure.

Conclusion A three-hour workshop may promote awareness, increase confidence and may enable change to practice.

\section{P-122 REFRACTORY ANGINA IS A GROWING CHALLENGE FOR PALLIATIVE CARE: A SYSTEMATIC REVIEW OF INTERVENTIONS}

1,2lain Murphy, Akshara Sivashankar ${ }^{3}, 1,2$ Amy Gadoud. 'Trinity Hospice, Blackpool, UK; ${ }^{2}$ Lancaster University, Lancaster, UK; ${ }^{3}$ Lancashire Teaching Hospitals, Preston, UK

\subsection{6/bmjspcare-2019-HUKNC.145}

Background Refractory angina is a chronic and potentially debilitating condition that is estimated to affect $30-50,000$ new patients per year in Europe. It is likely to become more prevalent as the likelihood of survival with ischaemic heart disease increases. There is a demand for palliative intervention in patients whose quality of life is significantly affected and where conventional medical treatment and revascularisation 